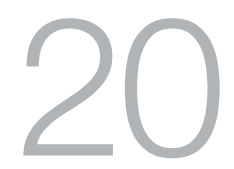

\title{
A Governance Framework for Indigenous Ecological Knowledge Protection and Use
}

\author{
Natalie P Stoianoff ${ }^{1}$
}

\section{Introduction}

Indigenous communities hold knowledge critical to the conservation of biological diversity and natural resource management. This Indigenous ecological knowledge (IEK) is increasingly recognised as a more effective means of managing the Australian landscape given the holistic approach of understanding the seasons, biodiversity, land and water. ${ }^{2}$ The threat of intergenerational loss of such knowledge about Country is a wellrecognised issue creating cause for concern for the knowledge holders, their communities and the whole of humanity. Protecting IEK benefits not only Indigenous Australian and local communities but also the longterm economic security and sustainable development of Australia.

Despite numerous consultations, reports, landmark cases, suggested protocols, models and draft legislation, Australia has been slow to meet international expectations in providing an effective mechanism for

1 Professor Stoianoff is the Director of the Intellectual Property Program in the Faculty of Law at the University of Technology Sydney and Chair of the Indigenous Knowledge Forum Committee. 2 Commonwealth of Australia, Caring for Our Country - Outcomes 2008-2013 (2013), 21, 31, $36-37,39$. 
recognising and protecting Indigenous knowledge and culture. ${ }^{3}$ Confusion as to whether intellectual property law (federal law) or environmental law (state law) provides the appropriate mechanism for such protection is a contributing factor.

The legislative solution proposed by the 2014 White Paper, Recognising and Protecting Aboriginal Knowledge associated with Natural Resource Management, prepared for the Office of Environment and Heritage New South Wales (NSW) (the NSW White Paper) ${ }^{4}$, provides a solution that may operate at state level or be adopted federally. It establishes a competent authority and governance framework to administer a protection, access and benefit sharing regime. It recognises concerns that community consultation has raised about the form such an authority would take, its independence from government, how it would be funded and wound up, local Aboriginal representation and engagement. This chapter reports on the making of such a governance framework.

\section{Theoretical Framework}

The theoretical framework for this chapter is drawn from the principles established in the Convention on Biological Diversity (1992) (CBD) ${ }^{5}$, expanded in the Nagoya Protocol $(2011)^{6}$, and reinforced in the United Nations Declaration on the Rights of Indigenous Peoples (2007) $(\mathrm{UNDRIP})^{7}$. These principles provide Indigenous knowledge holders with a right to share in the benefits obtained from the use of their knowledge, emphasising the need for free prior informed consent to be given by the knowledge holders prior to access and use of that knowledge on mutually agreed terms. Action research and Indigenous research

3 Natalie Stoianoff and Alpana Roy, 'Indigenous Knowledge and Culture in Australia - The Case For Sui Generis Legislation', Monash University Law Review (Vol 41, No 3) 745-46.

4 UTS Indigenous Knowledge Forum and North West Local Land Services (2014), Recognising and Protecting Aboriginal Knowledge Associated with Natural Resource Management, White Paper for the Office of Environment and Heritage NSW, indigenousknowledgeforum.org/components/com content/models/forms/white_paper.pdf.

5 Convention on Biological Diversity, opened for signature 5 June 1992, 1760 UNTS 79 (entered into force 29 December 1993) ('CBD').

6 Nagoya Protocol on Access to Genetic Resources and the Fair and Equitable Sharing of Benefits Arising from their Utilization to the Convention on Biological Diversity, opened for signature 2 February 2011 (entered into force 12 October 2014) ('Nagoya Protocol').

7 United Nations Declaration on the Rights of Indigenous People, GA Res 61/295, UN GAOR, 61st sess, 107th plen mtg, Agenda Item 68, Supp No 49, UN Doc A/RES/61/295 (13 September 2007). 
paradigm methodologies were utilised by the author and her research team in developing the legal framework for a regime that encapsulates these principles.

The focus was on the Aboriginal communities of Northwest NSW and accordingly reflects the concerns and interests of those communities while incorporating the international law principles described above. This was achieved through an initial comparative analysis of regimes existing in other nations, the establishment of a highly skilled and multidisciplinary Working Party of Indigenous and non-Indigenous individuals and stakeholders, and finally through Aboriginal community consultation.

\section{Principles for a Governance Framework of Recognition and Protection}

Several international instruments recognise the significance of traditional and Indigenous knowledge and cultural expressions, and emphasise the need to respect, preserve and maintain knowledge, innovations and practices of Indigenous and local communities. ${ }^{8}$ For example, the CBD provides member nations with the opportunity to establish regimes that regulate foreign and domestic access to valuable genetic resources and traditional and Indigenous knowledge while enabling benefit-sharing mechanisms for such access. ${ }^{?}$

This has led to significant international debate on the interrelationship between IEK and intellectual property rights, particularly patents and plant breeders' rights developed from genetic resources. The role of IEK in this context is significant as it brings into the equation the broader cultural property of Indigenous and local communities. Meanwhile, Art 11 of UNDRIP recognises the right of Indigenous people 'to practise and revitalize their cultural traditions and customs' and extends to 'the right to maintain, protect and develop the past, present and future manifestations of their cultures'. The state is expected to develop with Indigenous peoples effective compensation mechanisms 'with respect to their cultural, intellectual, religious and spiritual property taken without their free, prior and informed consent or in violation of their laws, traditions and customs'. ${ }^{10}$

8 See Stoianoff and Roy, above n 3, 753-68.

9 CBD, Arts 8j, 10(c) and 18(4).

10 UNDRIP, Art 11. 
Many nations and regions have adopted legal instruments covering such rights. Nations utilising sui generis legislation ${ }^{11}$ to do so include Brazil, ${ }^{12}$ Peru, ${ }^{13}$ Panama ${ }^{14}$ and the Philippines ${ }^{15}$ requiring the establishment of registers or databases and a representative authority. Some of these legal instruments are based on the WIPO-UNESCO Model Provisions, ${ }^{16}$ containing intellectual property type provisions. At the same time, the Pacific Regional Framework for the Protection of Traditional Knowledge and Expressions of Culture (2002) provides the Model Law for the Protection of Traditional Knowledge and Expressions of Culture 2002 which sets out cultural rights and moral rights over traditional knowledge and expressions, the need for prior informed consent, a mechanism establishing applications for use and identifying the traditional owners, authorised user agreements, civil and criminal enforcement including defences, and a cultural authority to oversee the regime. Other regional solutions are found in Africa, ${ }^{17}$ the Andean Community of Nations, ${ }^{18}$ and ASEAN. ${ }^{19}$

The CBD provides that alternative mechanisms (guidelines, sui generis systems or ethical codes of conduct) can be utilised for respecting, preserving and maintaining Indigenous or traditional knowledge. ${ }^{20}$ Some Australian jurisdictions have their own approach to dealing with

11 Intergovernmental Committee on Intellectual Property and Genetic Resources, Traditional Knowledge and Folklore (2012), Glossary of Key Terms Related to Intellectual Property and Genetic Resources, Traditional Knowledge and Traditional Cultural Expressions, Twenty-Second Session, Geneva (July 9 to 13,2012 ).

12 Law No 13.123 of May 20, 2015 (Access and Benefits Sharing of Genetic Resources and Associated Traditional Knowledge) (Brazil).

13 Law No 27,811 of 2002 Introducing a Protection Regime for the Collective Knowledge of Indigenous People Derived from Biological Resources (Peru).

14 Law No 20 of June 26, 2000, on Special System for the Collective Intellectual Property Rights of Indigenous Peoples for the Protection and Defense of their Cultural Identity and their Traditional Knowledge (Panama).

15 Indigenous Peoples Rights Act of 1997 (Philippines).

16 Model Provisions for National Laws on the Protection of Expressions of Folklore Against Illicit Exploitation and Other Prejudicial Action (UNESCO and WIPO, 1982).

17 See the Organisation of African Unity, Model Legislation for the Protection of the Rights of Local Communities, Farmers and Breeders, and for the Regulation of Access to Biological Resources, 2000; and the African Regional Intellectual Property Organization, Swakopmund Protocol on the Protection of Traditional Knowledge and Expressions of Folklore (2010).

18 Common Regime on Access to Genetic Resources, Decision 391, 2 July 1996, Official Gazette 17 July 1996.

19 ASEAN Framework Agreement on Access to Biological and Genetic Resources, 24 February 2000 (draft).

20 See COP 5 Decision V/16, www.cbd.int/decision/cop/default.shtml?id=7158. 
IEK using voluntary protocols rather than mandatory obligations, ${ }^{21}$ with varying degrees of success. The Australian Government has said that its domestic measures are consistent with the Nagoya Protocol. ${ }^{22}$ This may be true of protecting Australia's genetic resources but is questionable in the case of associated IEK. The Nagoya Protocol requires that where 'Indigenous traditional knowledge [is utilised] countries have to make sure that the knowledge was acquired in accordance with the rules of the country where those Indigenous people live'. ${ }^{23}$ This requires the prior informed consent of the Indigenous community that is providing the knowledge, on mutually agreed terms, an element that some Australian jurisdictions fail to include in their access and benefit-sharing legislation for genetic resources. ${ }^{24}$

Collaboration between the United Nations Environment Programme (UNEP), responsible for the introduction of the CBD, and the World Intellectual Property Organization (WIPO) resulted in the WIPO General Assembly establishing the Intergovernmental Committee on Intellectual Property and Genetic Resources, Traditional Knowledge and Folklore (IGC) in 2000. ${ }^{25}$ This committee has been negotiating international instruments for the protection of traditional or Indigenous knowledge and culture from an intellectual property perspective, and has produced three draft international instruments.

Adjei and Stoianoff point out that there are eight key elements to a framework of protection for traditional knowledge:

1. The meaning of traditional knowledge and its scope.

2. The identification of beneficiaries.

21 See, for example, the Queensland Code of Ethical Practice for Biotechnology 2001 superseded by the Queensland Biotechnology Code of Ethics (updated 2006) which applies to organisations conducting biotechnology research with Queensland Government funding, www.qld.gov.au/dsiti/assets/documents/ qld-biotechnology-code-of-ethics.pdf. See also the Indigenous Ecological Knowledge Manual by Territory Natural Resource Management, media.wix.com/ugd/da28f0_624bf834d6ef4672b98820bac2b77283. pdf. For a more local example, see the draft Blue Mountains City Council's Aboriginal Cultural Protocols 2010 which applies to councillors and council staff.

22 Australian Government, 'The Nagoya Protocol in Australia' (2015), www.environment.gov.au/ system/files/pages/9fc06ac0-f5af-4b47-a80f-d9378088d743/files/nagoya-factsheet_1.pdf.

23 Ibid.

24 For example, Biodiscovery Act 2004 (Qld).

25 UNEP and WIPO jointly commissioned a study on the issue of how intellectual property rights can support the objectives of the $\mathrm{CBD}$, in particular, what role such rights can play in the process of benefit sharing: WO/GA/26/6, WIPO General Assembly, Twenty-Sixth (12th Extraordinary) Session, Geneva, September 25 to October 3, 2000, Matters Concerning Intellectual Property and Genetic Resources, Traditional Knowledge and Folklore, 2. 
3. The scope of protection: elements of confidentiality and moral rights, protecting against misappropriation and misuse.

4. Sanctions and remedies emulating those used in intellectual property law.

5. The need for disclosure in existing patent and plant variety rights regimes.

6. The establishment of a competent authority to manage the data, rights conferred, enforcement, dispute resolution and national treatment.

7. The creation of databases.

8. Accommodating trans-boundary cooperations where knowledge and biodiversity extend across national borders. ${ }^{26}$

The IGC is exploring a sui generis (stand alone) model for the protection of traditional knowledge, recognising that protecting such knowledge does not fit into the existing intellectual property paradigm due to the need for protection in perpetuity in accordance with cultural norms, the difficulty of identifying the 'author' or 'creator' of the knowledge, and the failure of conventional intellectual property to recognise communal rights over that knowledge. Consequently, the IGC embarked on a process of developing a protection model that will accommodate the peculiarities of Indigenous knowledge. The NSW White Paper $^{27}$ took a similar approach and developed such a sui generis model law.

The arguments for and against a sui generis law were acknowledged..$^{28}$ International support for a sui generis regime was evident from WIPO, UNEP and the Conference of the Parties for the CBD. ${ }^{29}$ Customary laws could be incorporated into such a regime taking into account needs and expectations of Indigenous and local Communities, [enabling] protect[ion of the] integrity of traditional knowledge and [punishing] use that offends Indigenous and local Communities while encouraging acceptable use by third parties' ${ }^{30}$ If IEK is to be recognised as part of a living culture that requires access to Country for it be preserved, maintained, respected and developed in accordance with customary laws, crossing the thresholds of

26 Patricia Adjei and Natalie P Stoianoff (2013), 'The World Intellectual Property Organisation (WIPO) and the Intergovernmental Committee: Developments on Traditional Knowledge and Cultural Expressions', Intellectual Property Forum, Issue 92, March 2013, 37-48.

27 UTS (2014), above $\mathrm{n} 4$.

28 Ibid

29 Ibid

30 Ibid. 15. 
intellectual property type rights and environmental responsibilities, then the legal framework must be inevitably unique, hence the need for a sui generis law. ${ }^{31}$

\section{Method and Methodology}

The inaugural Indigenous Knowledge Forum held at the University of Technology, Sydney, (UTS) in August 2012 inspired the design of the NSW White Paper project which engaged the Namoi Catchment Aboriginal Community in developing a model of involvement in natural resource management and access to Country. ${ }^{32}$ The project was funded by the Aboriginal Communities Funding Scheme of the Namoi Catchment Management Authority (now North West Local Land Services (NWLLS)) with the advice of the Aboriginal Officer and the Namoi Aboriginal Advisory Committee (NAAC). It was carried out in three stages, commencing with development of a comparative framework, followed by drafting of the sui generis regime, and Aboriginal community consultation to refine the regime. The first stage involved a doctrinal comparative study, analysing legislative and policy regimes operating around the world. Key criteria in each regime were identified and then compared to international obligations. This comparative analysis provided the framework on which a model could be developed to ensure the recognition and protection of IEK.

In stage two, a working party was formed to assist in developing a sui generis regime, comprising Indigenous and non-Indigenous members from the UTS Indigenous Knowledge Forum committees, ${ }^{33}$ participants from the 2012 Indigenous Knowledge Forum, and key personnel from the NWLLS and the NAAC.

A Discussion Paper incorporating the Comparative Study Report and Draft Regime was prepared, and in stage three it was distributed through the NWLLS to the Namoi Catchment Aboriginal Communities and other interested parties. Consultation sessions were conducted on Country according to relevant cultural norms and protocols in key locations in

31 Chidi Oguamanam, International Law and Indigenous Knowledge: Intellectual Property, Plant Biodiversity and Traditional Medicine (University of Toronto Press, Toronto, 2006) 217-19.

32 Indigenous Knowledge Forum Report (2012), indigenousknowledgeforum.org/images/ikf-report. pdf.

33 The Organising Committee and the Advisory Board. 
the region. The consultations tested the draft legal framework against Aboriginal community concerns and expectations, thereby enabling it to be refined into a culturally acceptable model which was set out in the NSW White Paper and presented to the Office of Environment and Heritage.

The project addressed the need for recognition and protection of IEK by engaging the local, grassroots level, employing variations of an action research methodology coupled with an Indigenous research paradigm at both stages two and three of the project. Indigenous Australians were given an opportunity to actively participate in the process of formulating legislation for their benefit. The action research methodology emphasises cooperative or collaborative inquiry ${ }^{34}$ whereby all active participants, Indigenous and non-Indigenous, are fully involved in research decisions as co-researchers. ${ }^{35}$ Through the internet, the project provided all interested parties with access to analysis of current models for, and outcomes of implementing, similar legislation in other countries. This assisted in the process of identifying how best to accommodate unique aspects of IEK and culture as they relate to the interests of Indigenous Australians.

Participation assisted in generating Indigenous ownership of the outcomes, understanding of any resulting legislation and its intent, and an opportunity to deliver robust legislation that meets Australia's international obligations and effectively protects the interests of an important sector of the Australian community. During stage two the Indigenous research paradigm was important in engaging all participants in the collection of research data through the method of storytelling by Indigenous Elders in the group, exploring meaning and working through issues together to ensure accurate interpretation of language. ${ }^{36}$ This process was then adopted during consultations on Country, being mindful of the culture of place and the privilege of sharing in the flow of cultural knowledge.

34 John Heron, Co-operative Inquiry: Research into the Human Condition (Sage, London, 1996).

35 Peter Reason and Hilary Bradbury, Handbook of Action Research (Sage, London, $2^{\text {nd }}$ edn, 2007).

36 Ewa Czaykowska-Higgins, 'Research Models, Community Engagement, and Linguistic Fieldwork: Reflections on Working within Canadian Indigenous Communities', Language Documentation \& Conservation 3(1), June 2009. 


\section{Results and Conclusions}

The key outcome of this project was the development of a legislative regime that facilitates the recognition, preservation and protection of IEK, enabling its custodians to share in the benefits of its use. The resulting draft legislation, explained in the NSW White Paper, ${ }^{37}$ sets out key principles rather than detailed prescriptive provisions which are left to regulations that would need to be implemented.

The preamble of the draft legislation recognises the impact of European arrival on IEK and connection to Country of Aboriginal peoples, and sets out the aims of the legislation. Section 1 establishes the rights of Aboriginal communities over their knowledge. Key terms are defined in $s 2$ and the beneficiaries under the legislation are identified in $s 3$. The process of access to the knowledge is described in $s 4$, and guidelines for benefit-sharing are set out in 5 . Sanctions and remedies for breaches of the legislation are provided for in $s 6$, emulating remedies available for infringement of intellectual property rights with penalties ranging from fines to imprisonment. Section 7 requires the establishment of a Competent Authority to administer this regime including managing databases to enable the access process to operate. Section 8 provides for dispute resolution where there are multiple communities claiming 'ownership' of the same or similar knowledge. Every regime requires a set of express exceptions and $s 9$ provides for that eventuality. The nature of the three types of databases and the obligations regarding disclosure are dealt with in $s 10$. The remaining three provisions are general in nature, dealing with interaction between existing laws (s 11), mutual recognition of rights and compliance (s 12), and transitional provisions (s 13).

Although the NSW White Paper $^{38}$ provides a fictitious case study to demonstrate the operation of the draft regime, it does not claim to provide a complete solution for recognition and protection of IEK. Shortcomings include the need to clarify the form and nature of the Competent Authority and governance processes; the way the databases are to be formed, funded and managed from community level to state and national levels; and the administration processes for access and benefit-sharing, including guidance on mutually beneficial terms, model agreements and processes for negotiation. 
Introducing such a regime has beneficial flow-on effects including:

a. Recognition that IEK is part of a living culture that requires access to Country for it to be preserved, maintained respected and developed;

b. A mechanism for documenting, recording and recovering IEK for future generations of Indigenous Australians;

c. A response to intergenerational loss of knowledge about Country (land and water) by encouraging younger generations to spend time on Country with their Elders to regain their traditional language and oral tradition through which culture and knowledge are maintained;

d. Improved natural resource management by facilitating access to Country, aimed at both Indigenous engagement and sustainable use of IEK; and

e. Recognition that IEK is to be valued and utilised in accordance with Indigenous protocols that govern use and dissemination of this knowledge, including the need for prior informed consent and the establishment of an appropriate benefit sharing arrangement on mutually agreed terms.

IEK is of significant spiritual, cultural and economic value not only to Aboriginal and Torres Strait Islander communities but also to society at large, including governments, research institutions and commercial interests. ${ }^{39}$ As Australia moves towards ratification of the Nagoya Protocol, two main measures require implementation: ensuring (i) that prior informed consent of Indigenous communities is obtained for access to their traditional knowledge, and (ii) that fair and equitable benefit-sharing mechanisms are agreed on for the use of that knowledge, consistent with community laws and procedures as well as customary use and exchange. ${ }^{40}$ The governance framework espoused in the NSW White Paper addresses these expectations. The journey continues towards the goal of determining the nature of the Competent Authority required to administer the framework. The author and her research team has been awarded an ARC Linkage grant for the project, Garuwanga: Forming a Competent Authority to Protect Indigenous Knowledge, and will work towards achieving that goal over the next three years.

39 Susette Biber-Klemm and Danuta Szymura Berglas, 'Problems and Goals' in Susette BiberKlemm, Thomas Cottier and Danuta Szymura Berglas (eds), Rights to Plant Genetic Resources and Traditional Knowledge: Basic Issues and Perspectives (CAB International, 2006) 3, 21.

40 Nagoya Protocol, Arts 7 and 12. 
While New South Wales has made little progress on implementing a regime along the lines recommended by the White Paper, the State of Victoria has recently amended its Aboriginal Heritage legislation to establish a database system to protect Aboriginal intangible heritage, ${ }^{41}$ which is another way of describing Indigenous knowledge or IEK. Further, IP Australia invited the submission of the NSW White Paper to the Indigenous Knowledge Consultation which is about to move to the next stage of preparing a discussion paper. We are hopeful that the model provided by the NSW White Paper may encourage the creation of a national scheme of protection of IEK. 
This text is taken from New Directions for Law in Australia: Essays in Contemporary Law Reform, edited by Ron Levy, Molly O’Brien, Simon Rice, Pauline Ridge and Margaret Thornton, published 2017 by ANU Press, The Australian National University, Canberra, Australia. 